\title{
The Association Between Learning Style, Learning Strategies with Academic Performance Among Nursing Students
}

\author{
Nadia Nosheen \\ School of Nursing, University of Lahore \\ Muhammad Hussain \\ School of Nursing, University of Lahore
}

\begin{abstract}
Background: One of the most important problems in student's education is academic failure. Identifying factors that affecting academic achievement and pay attention to these factors is a stride toward success. Students' academic achievement and related factors have priority in education research.

Objective: The objective of present study was to evaluate the association between learning styles and learning strategies on academic performance among nursing students.

Materials and Methods: A Co-relational study was conducted in The University of Lahore. In this study 109 students were selected via convenient sampling. In this study co-relation test was used to assess the association between learning styles and learning strategies on academic performance among nursing students.

Results: According to correlation coefficients, there is a positive significant relationship between students learning styles (.060) and learning strategies (.013) and p value is less than 0.01.

Conclusion: Considering positive and significant correlation between learning and study strategies with academic achievement in nursing students, so, we suggest that students and teachers use these strategies to improve academic achievement and reduce the academic loss of students.
\end{abstract}

Keywords: Learning. Learning styles. Learning strategies. Academic performance. Students

DOI: $10.7176 / \mathrm{JHMN} / 72-08$

Publication date:March $31^{\text {st }} 2020$

\section{Introduction}

Learning is an interactive process and is the product of student and teacher activity within a learning environment. It is characterized as including all learning exercises embraced all through life, with the point of improving information, aptitudes and skills, inside individual, municipal, social and additionally business-related perspective (Goldie, 2016).

The academic performance is an directly observable indicator of learning. Academic performance refers to the efficiency learning from the mobilization of cognitive and emotional-volitional resources of the student when he faces with a certain work task. The performance represent the level of obtained academic results, the quantitative and qualitative changes in academic purchases. Student learning performance can be imagine and explained with a certain degree of probability if are known the factors that influence them and the way that their effects are distributed (Magdalena, 2015).

Academic learning is a category of learning that which has high quality of characteristic, for example, intrinsic motivation, self-control, self-direction and self-regulation, of the activity of the students. It is important to involve learners in the process of setting their own direction and means of learning and evaluation as a way of facilitating their personal autonomy and self-direction (Yazan, 2015).

Many researchers have described the learning styles in different ways. Kolb classify a process of learner's styles as convergent, divergent, assimilators and accommodators. Honey and Mumford make easier to understand the learning styles as activists, reflectors, theorists and pragmatists. This study established the shape of the frequency of learning styles (Honey and Mumford) of medical and nursing students and its correlation with elaborate teaching methodologies and academic achievements (Moayyeri, 2015).

Learning style was also defined additionally characteristic of an individual who communicate with instructional circumstances in such an approach to create differential learning results. A student learning style impact their embraced problem-solving method of (experimenting, conceptualizing, reflective, observation)(Lenette, 2016).

Learning is an activity in which knowledge generate through the transformation of experience. Whatever, successful learning only happens when a learner can implement all four stages of the model. Hence, no one stage of the cycle is effectual as a learning procedure on its own (DeCoux, 2016). However, effective learning only occurs when a learner can implement all four stages of the model. Therefore, no one stage of the cycle is effective as a learning procedure on its own (McLeod, 2010). Kolb learning style model produced in 1984 from which he elaborates his inventory learning style. Kolb learning style constitute a four-stage learning cycle in which learner experienced all bases of learning style. For example Diverging (feeling and watching) and also called reflector 
learning style, Assimilating (watching and thinking) and also called Theorist learning style, Converging (doing and thinking) and also called pragmatist learning style, Accommodating (doing and feeling) and also called activist learning style (Alkan, 2016).

The present study proposes to analyze the relationship among the students' learning style, learning strategies and academic performance among nursing students. Learning strategies were calculated using a self-regulated learning with sub items are (rehearsal, organization, elaboration and critical thinking) (Magdalena, 2015).

Learning strategies expressed by a rules, method and principles used to smooth the pathway of learning. When learning strategies implement, leads to active learning because it instructs how to learn and how to successful. If we desired to produced good learning result it is compulsory to use numeral combination of learning strategies (Susnea, Pecheanu, Dumitriu, \& Cocu, 2017).

A standout amongst the most imperative issues in understudy's training is academic failure. Distinguishing factors that influencing academic accomplishment and focus on these elements in a specific direction. Student's academic accomplishment and related components have need in instruction inquire about. This examination meant to decide the connection between learning study techniques and scholarly accomplishment of nursing students. Moreover, if the instructing methodology that the teacher utilized is obliged the learning style of the students, this system will impact the academic performance to some degree. In view of understudy input, learning strategies ought to be continually updated to suit the learning style of the understudies (Maman \& Rajab, 2016).

\section{AIMS OF THE STUDY}

Aim of the study is to analyze the relationship between learning styles, learning Strategies and outcomes among nursing students.

\section{SIGNIFICANCE OF THE STUDY}

This study finding will provide the information regarding the relationship of learning styles and learning strategies with academic performance, to the policy maker, decision maker on behalf of this study information concerning authority will take sufficient measure like workshop, seminar to enhance the learning styles, learning strategies of nursing students which ultimately positively effect on academic performance of nursing students. This action may improve the quality of education and enhance the students learning.

\section{LITERATURE SEARCH}

There are several identified learning styles: Kolb's learning styles model, Honey and Mumford's learning styles model[8], Felder Silverman's learning style model[6] and VARK based learning style. Kolb's model is made up of four cycles of learner behavior in gaining new knowledge. The first cycle begins with Concrete Experience (CE), which is an activity conducted directly by learners in attempt to find a solution to the problem. Kolb called this process feeling. To ensure that the acquired knowledge is the answer of the problems, the learner needs to reobserve his experience. This is called Reflective Observation (RO). In this process, learners directly observe through visual means. This visual observation is known as watching by Kolb. The next process of the visual observation result or watching is a concept known as Abstract Conceptualization (AC). The narration of knowledge obtained from $\mathrm{CE}$ and $\mathrm{RO}$ is then written in AC. Kolb called this learning style thinking. The final step is Active Experimentation (AE), which is a direct activity process to ensure the return of the experience (feeling), observation (watching), and concept (thinking). This step is known as doing (Arslan, 2018).

The Honey and Mumford's Activist learning style theory is similar to Kolb's Accommodating learning style, Activist learners prefer learning activities that involve directly accessing the teaching materials or known as kinesthetic. The Activist learners do not enjoy the process of reading, writing and listening as much. Unlike Reflector learning style, which is similar to the Diverging learning style of Kolb, the Activist prefers observation to gain knowledge.

The Reflector learner type applies a great deal of consideration and tends to learn through the process of visually, seeing, reading and hearing (Arslan, 2018). The Theorist prefers the learning process to be conceptually derived from the theory of multiple books. More in-depth and structured knowledge is gained. In Pragmatics, the learners gain knowledge by discussing a topic and then associating it with existing theory. Pragmatic learners generally prefer learning from discussion forums, listening and engaging directly (kinesthetic).

Leaning style originate from the concept of style, there is lack of concept agreement over the basic terminology. The term has been used in various and sometimes confusing ways in the literature, often interchangeably with the term of cognitive styles, affective styles, or learning strategies. Cognitive styles and affective styles are only sub constructs of learning styles and learning styles are more comprehensive. Cognitive styles are often described to individual perception and approach to organize and represent information. Its important dimensions are field dependent and field independent, leveling and sharpening, holist and serialist, impulsive and reflective and abstract and concrete (Shadiev \& Huang, 2016).

A study was conducted on to analyze the relationship of learning style, learning strategies and academic 
performance among nursing student. In this study we report the experiential learning model- Kolb because it seems more suitable for specific learning activity of students in the academic program-preschool and primary pedagogy.

According to Kolb, learning style is not a suitable trait, but a preference for learning preference that is slowly changing from one situation to another. This model described to compare Wolf \& Kolb (1984) of four learning styles of students according to preference for a particular approach to task and active strategies to sort out. The first dimension related to the perception of thinking (concrete or abstract) and the second dimension describes information processing (active or reflective)(McGovern \& Burns, 2016).

Learning style have received considerable attention in recent year. There are more than 20 style dimensions that have been identified so far. It has come out of the more general research on cognitive styles. The earliest and frequently discussed dimension of learning styles is the concept of field dependence and field independence that is advocated by psychologist (Yassin \& Almasri, 2015).

Kolb's (1976) experimental learning theory is prevalent in educational setting, because his theory explains more about the teaching and learning process. Many researchers and instructors have adopted his theory and applied into different educational areas. The most important thing is that he has explained four learner type on the basis of his learning theories and four learner types are convergent, divergent, assimilator and accommodator.

Claxton and Murell (1987) use an onion metaphor to describe the multi-constructs of learning styles. The multi-constructs of learning styles are compared as the layer of an onion. The core is composed of personality characteristics, then from inside to outside, the layers are sequentially information -processing the second layer, social interaction the third layer and instructional layer the forth and the outermost layer. The core is the constant and stable part, but the successive layer around it can be slightly changed to some extent (Shadiev \& Huang, 2016).

Chuah Chong-Cheng (1988) discusses the importance of learning styles as being not only necessary, but also important for individuals in academic settings. Most students favour to learn in particular ways with each style of learning contributing to the success in retaining what they have learnt. As such, studies carried out conclude that students retain $10 \%$ of what they read, $26 \%$ of what they hear, $30 \%$ of what they see, $50 \%$ of what they see and hear, $70 \%$ of what they say, and $90 \%$ of what they say as they do something (Arjulayana, 2016).

These facts reveal that each learning style has its own strengths and weaknesses. Some students learn in many ways, while others might only favour one or two. Those students with multiple learning styles tend to gain more and obtain higher scores compared to those who rely solely on one style (Dunn, Beaudry \&Klavas 1989). Additionally, the differences in learning styles have also been reported between gifted and the underachievers; between the learning disabled and average achievers; among different types of special education students; and among secondary students in comprehensive schools and their counterparts in vocational education and industrial arts (Dunn \& Dunn 1986). Some special students favour Kinesthetic instruction, such as experiential, active and hands-on, while many others are more auditory and visually oriented (Pruet, Ang, \& Farzin, 2016).

\section{METHODOLOGY}

SETTING

The setting will include nursing students between the age of 19 and 49 years, students in the program of study 2 Year Post RN (BSN) and 4 Year Generic (BSN) students of University of Lahore.

RESEARCH DESIGN

The quantitative co-relation study design will use to explore knowledge of relationship between learning style, leaning strategies and academic performance among nursing students at University of Lahore

POPULATION

The sample size will be 109 students of BSN, Post RN students.

SAMPLING

A convenient sampling technique will be used, which is non probability sampling method.

RESEARCH INSTRUMENT

A questionnaire was designed for this study to gather data to answer the research questions.

DATA GATHERING PROCEDURE

A formal written letter of permission to conduct the research. And questionnaire was distributed in nursing students. ANALYZE DATA

Data will be analyzed through Statistical Package for the social science (SPSS). 21 versions.

The correct and suitable analysis of research result is ensuring data reliability.

STUDY TIMELINE

The data was collected from Jan 28, 2019 to April 17, 2019.

\section{ETHICAL CONSIDERATION}

The study will be conducted in 2 Year Post RN (BSN) and 4 Year Generic (BSN) students of University of Lahore. After a permission letter from institutional review board committee of University of Lahore.

The rules and regulations of college will not violated 
Each member who will participant in this study will be dealt in respective way.

All information will be confidential. Volunteer right will be maintained.

\section{RESULTS}

Results consist of three parts, the first part related to personal and social characteristic (demographic data) such as gender, age, academic rank, economic status, marital status and CGPA. The second part consist of forty question of learning styles and third part consist of thirty one question of learning strategies.

The mean, median, mode and standard deviation of demographic data. The mean score of the gender of the participants was 2.02 , median was 2.00 , mode was 2 , and standard deviation of gender of the participants was 2.061. The mean score of the age of the participants was 1.72 , median was 2.000 , mode was 2.00 , and standard deviation of the age of the participant was .692. The mean score of academic rank of the participant was 1.67 , median was 2.000, mode was 2.00 and standard deviation of the academic rank of the participants was .469. The mean score of economic status of the participants was 3.36, median was 4.000 , mode was 4.00 and standard deviation of the participants was 1.111. The mean score of the participants of marital status was 1.633 , median was 2.000, mode was 2.00 and the standard deviation of the marital status of the participants was .538. The mean score of the CGPA of the participants was 2.00 median was 2.000 , mode was 1.00 and the standard deviation of the CGPA of the participants was 937.

\section{DISCUSSSION}

The current study was conducted to determine the presence of a relation- ship between learning styles, learning strategies and academic performance among nursing students. Learning styles are ways of learning by the students. The gathered data by apply statistical tools have undergone specific analysis and have obtained the following results. The Pearson co- relation analysis of data collected reveals that in term of preferred learning style of the students it has the following distribution; Divergent style 55\%,16\% convergent style, assimilator style $11 \%$ and accommodator style $15 \%$.

Regarding the distribution of subjects according to the learning style variable $(.060, \mathrm{P}<0.01)$. Regarding the distribution of score according to the academic rank are significant difference in term of preferred learning styles. In term of learning strategy, Pearson co-relation analysis reveal the following distribution: .058\% use surface learning rehearsal, . $107 \%$ use elaboration, $-.036 \%$ use organization , $-.005 \%$ use critical thinking and $-.019 \%$ use meta-cognitive self regulating. The analysis of learning styles and performance at theoretical activities or practical activities by co-relation method found significant relationship $\mathrm{P}<0.01$.

In term of relationship between learning styles and learning strategies result are presented in table 3 , and found association between variables. This study found data to the learning style level we identify all the styles described by Kolb, and found significant association between learning styles and learning strategies : further study can be developed to determine the predictive relationship between learning styles and learning strategies. In term of the relationship between learning style and academic performance results are differential so meta-cognitive performance associated with theoretical and practical experience at students with work experience and deep learning strategies is associated with high performance at the theoretical activities to students who do not have professional experience use instructional strategies differentiation in relation to the type of learning(mainly theoretical and / or practical, teacher use instructional strategies differentiation in relation to the type of learning . Flexibility in training leads to academic success, to the formation of specific skills for the study program that students follow, and having as a final goal a good insertion in the labor market.

\section{CONCLUSION}

This present study confirms that at the students level we can identify different learning styles: the divergent style, convergent style, assimilation style and accommodation style, and, also, the relationship that is established between learning style, learning behavior and academic performance of the students. It reveals differences between the learning behavior and the type of learning activities in which the student is involved (theoretical or practical). The study limits mainly refers to the number of subjects, to the low validity of the measuring instruments. Last but not least we believe that academic performance is influenced also by other factors like- personality factors, cognitive factors, motivational- emotional factors which were not considered student is involved (theoretical or practical).The study limits mainly refers to the number of subjects, to the low validity of the measuring instruments. Last but not least we believe that academic performance is influenced also by other factors like- personality factors , cognitive factors, motivational- emotional factors which were not considered in this study. We believe that providing an explanation of the factors influencing academic performance - learning style and strategies that meet students' needs and student is involved (theoretical or practical). The study limits mainly refers to the number of subjects, to the low validity of the measuring instruments. Last but not least we believe that academic performance is influenced also by other factors like- personality factors, cognitive factors, motivational- emotional factors which were not considered in this study. We believe that providing an explanation of the factors influencing 
academic performance - learning style and strategies that meet students' needs and student is involved (theoretical or practical).The study limits mainly refers to the number of subjects, to the low validity of the measuring instruments. Last but not least we believe that academic performance is influenced also by other preferences. By identifying learning styles in the educational context, and behaviors in their learning, teachers use instructional strategies differentiation in relation to the type of learning(mainly theoretical and / or practical, teacher use instructional strategies differentiation in relation to the type of learning. Flexibility in training leads to academic success, to the formation of specific skills for the study program that students follow, and having as a final goal a good insertion in the labor market.

\section{LIMITATIONS}

This study was limited by a co relational design and selection bias due to voluntary participation. Convenience sampling limits the generalization of the finding to the papulation. Homogeneity of the sample increased risk of bias by not using random sapling. All data were not collected during the same semester.

\section{ACKNOWLEDGEMENT}

I would like to thank the faculty of University of Lahore who contributed in many ways to this piece of work. First of all, I would like to thank Mr. Muhammad Afzal (The principal of Lahore School of Nursing) who allowed me to do this study and guided me. I would thank to Sir Hussain for the being my preceptor and for being the greatest inspiration for my work when I had no idea to perform a research work. I am indebted to him and I admire the way in which he explained very difficult concepts in very simple ways. He is very helpful in giving me suggestion. I would also like to thank all the participants and colleagues. Their participation made this study possible for me. It is a great pleasure to have all of those wonderful people in my life. I thank the management of University of Lahore.

\section{References}

Alkan, F. (2016). Experiential Learning: Its Effects on Achievement and Scientific Process Skills. Journal of Turkish Science Education (TUSED), 13(2).

Arjulayana, A. (2016). Indonesian Students' Learning Style in English Speaking Skill. Jurnal Dinamika UMT, $1(2), 1-9$.

Arslan, A. K. (2018). An exploratory model of learning styles based on agent learning. Advances in Higher Education, 2(2).

Batra, S., \& Vohra, N. (2016). Exploring the linkages of cognitive style and individual innovativeness. Management Research Review, 39(7), 768-785.

Bosman, A. (2015). The relationship between student academic achievement and student learning styles in a multicultural senior school.

DeCoux, V. M. (2016). Kolb's learning style inventory: A review of its applications in nursing research. Journal of Nursing Education, 29(5), 202-207.

Freiberg-Hoffmann, A., Stover, J. B., \& Donis, N. (2017). INFLUENCE OF LEARNING STRATEGIES ON LEARNING STYLES: THEIR IMPACT ON ACADEMIC ACHIEVEMENT OF COLLEGE STUDENTS FROM BUENOS AIRES. Problems of Education in the 21st Century, 75(1).

Goldie, J. G. S. (2016). Connectivism: A knowledge learning theory for the digital age? Medical teacher, 38(10), 1064-1069.

Lenette, C. (2016). University students from refugee backgrounds: why should we care? Higher Education Research \& Development, 35(6), 1311-1315.

Magdalena, S. M. (2015). The relationship of learning styles, learning behaviour and learning outcomes at the romanian students. Procedia-Social and Behavioral Sciences, 180, 1667-1672.

Maman, M., \& Rajab, A. A. (2016). The Implementation of Cooperative Learning Model" Number Heads Together"(" NHT") in Improving the Students' Ability in Reading Comprehension. International Journal of Evaluation and Research in Education, 5(2), 174-180.

McGovern, C., \& Burns, E. (2016). How instructional methods impact the learning and proficiency of entry level students manufacturing a wrist extension splint. Utica College.

McLeod, S. (2010). Kolb's learning styles and experiential learning cycle. Simply psychology.

Moayyeri, H. (2015). The impact of undergraduate students' learning preferences (VARK Model) on their language achievement. Journal of Language Teaching and Research, 6(1), 132-139.

Pruet, P., Ang, C. S., \& Farzin, D. (2016). Understanding tablet computer usage among primary school students in underdeveloped areas: Students' technology experience, learning styles and attitudes. Computers in Human Behavior, 55, 1131-1144.

Shadiev, R., \& Huang, Y.-M. (2016). Facilitating cross-cultural understanding with learning activities supported by speech-to-text recognition and computer-aided translation. Computers \& Education, 98, 130-141.

Susnea, I., Pecheanu, E., Dumitriu, L., \& Cocu, A. (2017). Exploring the connection between the students' 
creativity and summary writing skills. Paper presented at the 2017 IEEE Global Engineering Education Conference (EDUCON).

Yassin, B. M., \& Almasri, M. A. (2015). How to accommodate different learning styles in the same classroom: Analysis of theories and methods of learning styles. Canadian Social Science, 11(3), 26.

Yazan, B. (2015). Three approaches to case study methods in education: Yin: Merriam.

\begin{tabular}{|l|l|r|r|}
\hline \multicolumn{2}{|l|}{ Correlations } & Learning styles & Learning Strategies \\
\hline \multirow{3}{*}{ Learning styles } & Pearson Correlation & 1 & $.365^{* *}$ \\
\cline { 2 - 4 } & Sig. (2-tailed) & & .000 \\
\cline { 2 - 4 } & $\mathrm{N}$ & 107 & 106 \\
\hline \multirow{2}{*}{ Learning Strategies } & Pearson Correlation & $.365^{* *}$ & 1 \\
\cline { 2 - 4 } & Sig. (2-tailed) & .000 & 108 \\
\cline { 2 - 4 } & $\mathrm{N}$ & 106 & \\
\hline \multirow{2}{*}{$* *$ Correlation is significant at the 0.01 level (2-tailed). } & & \\
\hline
\end{tabular}

\section{Table: 1}

Table 1 represents the co relation between learning styles, learning strategies and academic performance among nursing students $\mathrm{p}$ value was $(<0.01)$ and Pearson correlation was $(.060$ and .013$)$ and sub domain was Rehearsal (.058), Elaboration (.107), Organization (-.036), Critical Thinking (-.005) and meta-cognitive self regulation $(-.019)$. It indicates that learning styles and learning strategies had a significant positive relationship with each other.

\begin{tabular}{|c|c|c|c|c|c|}
\hline Variable & Mean & Std. Deviation & Category & Frequency & Percent $=\%$ \\
\hline \multirow[t]{2}{*}{ Gender } & 2.0275 & 2.06137 & Male & 18 & 16.5 \\
\hline & & & Female & 90 & 82.6 \\
\hline \multirow[t]{3}{*}{ Age } & 1.7248 & .69217 & $17-25$ & 45 & 41.3 \\
\hline & & & $26-30$ & 49 & 45.0 \\
\hline & & & $31-35$ & 15 & 13.8 \\
\hline \multirow[t]{2}{*}{ Academic Rank } & 1.6789 & .46906 & $\mathrm{BSN}$ & 35 & 32.1 \\
\hline & & & Post RN & 74 & 67.9 \\
\hline \multirow[t]{4}{*}{ Economic status } & 3.3670 & 1.11106 & $5000-10000$ & 16 & 14.7 \\
\hline & & & $11000-15000$ & 6 & 5.5 \\
\hline & & & $16000-20000$ & 9 & 8.3 \\
\hline & & & $21000-25000$ & 78 & 71.6 \\
\hline \multirow[t]{4}{*}{ Marital status } & 1.6330 & .53853 & Married & 42 & 38.5 \\
\hline & & & Un married & 66 & 60.6 \\
\hline & 2.0092 & .93784 & $2.0-2.5$ & 39 & 35.8 \\
\hline & & & $2.6-3.0$ & 38 & 34.9 \\
\hline \multirow[t]{2}{*}{ CGPA } & & & $3.1-3.5$ & 24 & 22.0 \\
\hline & & & $3.6-4.0$ & 8 & 7.3 \\
\hline
\end{tabular}

Table: 2

Table 2 consist of three parts, the first part related to personal and social characteristic (demographic data) such as gender, age, academic rank, economic status, marital status and CGPA. The second part consist of forty question of learning styles and third part consist of thirty one question of learning strategies.

Fig 1

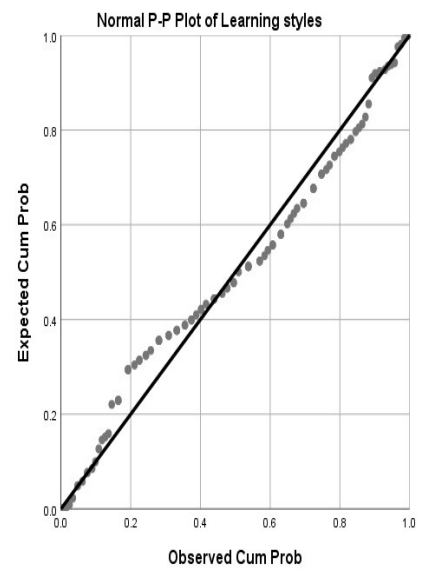

